\title{
Optimization of CVD parameters for long ZnO NWs grown on ITO/glass substrate
}

\author{
ABDULQADER D FAISAL \\ Applied Science Department, University of Technology, Baghdad, Iraq
}

MS received 12 December 2015; accepted 20 April 2016

\begin{abstract}
The optimization of chemical vapour deposition (CVD) parameters for long and vertically aligned (VA) ZnO nanowires (NWs) were investigated. Typical ZnO NWs as a single crystal grown on indium tin oxide (ITO)coated glass substrate were successfully synthesized. First, the conducted side of ITO-glass substrate was coated with zinc acetate dihydrate to form seed layer of $\mathrm{ZnO}$ nanocrystals. Double zone tube furnace connected to vacuum pump was used for $\mathrm{ZnO}$ growth process. $\mathrm{Zn}$ metal powder was positioned at the first zone at temperature $900^{\circ} \mathrm{C}$. The ITO-glass substrate with pre-coated seed layer was then located in the second zone of tube furnace at growth temperature of $550^{\circ} \mathrm{C}$. The growth of $\mathrm{ZnO} \mathrm{NWs}$ was controlled under constant concentration of seed layer, while other parameters such as argon and oxygen flow rates, substrate position, time and oxygen flow rate were varied. The VA ZnO NWs were finally characterized by scanning electron microscopy, X-ray diffractometer and highresolution transmission electron microscope equipped with energy-dispersive X-ray spectroscopy. The results show that long and VA ZnO NWs were single crystalline with hexagonal wurtzite structure. The ultimate length and average diameter of $\mathrm{ZnO} \mathrm{NWs}$ were $10 \mu \mathrm{m}$ and $50-100 \mathrm{~nm}$, respectively. These were achieved under optimized CVD growth parameters. The mechanism of vertical growth model of $\mathrm{ZnO}$ NWs is also discussed.
\end{abstract}

Keywords. VA ZnO NWs; chemical vapour deposition; long $\mathrm{ZnO}$ nanowires; $\mathrm{ZnO}$ single crystal; growth mechanism.

\section{Introduction}

Zinc oxide $(\mathrm{ZnO})$ is a II-VI compound semiconductor with a wide direct energy bandgap of $3.37 \mathrm{eV}$ and high exciton binding energy of about $60 \mathrm{meV}$ at room temperature [1,2]. $\mathrm{ZnO}$ as nanostructures have been found useful in many applications such as optoelectronics [3], photovoltaic [4], gas sensors [5], dye-sensitized solar cells [6,7], catalytic activity [8] and photo catalytic activity [9]. Several methods have been reported for the synthesis of various $\mathrm{ZnO}$ nanostructures, such as hydrothermal [10], sonochemical [11,12], sol-gel [13-15] and microwave irradiation [16]. Although conventional methods such as chemical vapour deposition (CVD) [17,18], vapour solid (V-S) [19], vapour trapping CVD [20], vapour phase transport deposition [21], electron beam evaporation [22] and thermal oxidation [23] can produce various $\mathrm{ZnO}$ micro or nanostructures, they often suffer from problems of high temperature, need for high vacuum, lack of control and high cost. It is crucial to have a controlled morphology of the nanostructures for the desired applications. Many different morphological $\mathrm{ZnO}$ nanostructures have been fabricated, including nanowires (NWs) [24], nanorods (NRs) [25,26], nanobelts [27], nanoflowers [28], nanospheres [29], nanorings [30], nanoribbon [31] and nanosaw [32]. In the present work, synthesis of long and vertically aligned (VA)

abdulf330@gmail.com
$\mathrm{ZnO} \mathrm{NWs}$ on indium tin oxide (ITO)-glass substrate was conducted with the optimization of CVD growth parameters.

\section{Experimental}

\subsection{ITO-glass substrate cleaning}

The ITO substrate cleaning is one of the conventional methods used to remove surface contaminants and to provide a clean ITO surface to enhance the adhesion of seed layer onto its substrates. So, the ITO-glass substrate was cleaned prior to the seed layer preparation. Pieces of ITO-coated glass $\left(1.0 \times 1.0 \mathrm{~cm}^{2}\right)$ substrates were gently washed with detergent solution and deionized (DI) water subsequently, then each of them were sonicated with acetone and isopropyl alcohol for $30 \mathrm{~min}$ and washed with DI water. Finally, they were dried under a stream of pure nitrogen and backed on hot plate at $150^{\circ} \mathrm{C}$ for $5 \mathrm{~min}$.

\subsection{Preparation of $\mathrm{ZnO}$ seeds layer}

The growth of $\mathrm{ZnO} \mathrm{NWs}$ begun firstly with $\mathrm{ZnO}$ seed layers coating as nanocrystals. The seed layer solution was always prepared by dissolving $0.015 \mathrm{M}$ of zinc acetate dihydrate [ $\mathrm{Zn}$ $\left.\left(\mathrm{CH}_{3} \mathrm{COO}\right)_{2} \cdot 2 \mathrm{H}_{2} \mathrm{O}\right]$ in $10 \mathrm{ml}$ of ethanol $\left(\mathrm{CH}_{3} \mathrm{OH}\right)$ and then sonicated for $30 \mathrm{~min}$. Later it was cooled down at room temperature to make it ready for use. The conductive side of 
ITO-glass substrate $\left(1 \times 1 \mathrm{~cm}^{2}\right)$ seed layer was coated by drop casting method using $20 \mu \mathrm{m}$ pipette. This layer was left for $20 \mathrm{~s}$ to interact with the surface. The ITO-glass with seed layer was rinsed with ethanol for few seconds and then followed by drying with a stream of $\mathrm{N}_{2}$ gas. The previous steps were repeated four times to insure having enough thickness of $\mathrm{ZnO}$ seed layer on the substrate. The seed layers coated on ITO-glass substrate became ready for loading into the quartz tube for simultaneous baking and growth processes.

\subsection{Growth parameters for $\mathrm{ZnO} N$ Ws on ITO-glass}

There are several CVD growth parameters of the ZnO NWs, which can be investigated in the present work. These parameters need to be selected properly during the growth of $\mathrm{ZnO}$ NWs on ITO-glass. The growth of the ZnO NWs were controlled under constant concentration of seed layer, while other parameters such as argon and oxygen flow rates, substrate position, time and oxygen flow rate were varied. The source temperature selection mainly depends on the volatility of the source material ( $\mathrm{Zn}$ powder). The substrate temperatures determine the morphology of $\mathrm{ZnO}$ nanostructure that will be grown on it.

\subsection{Growth process of ZnO NWs on ITO-glass}

The $\mathrm{ZnO}$ NWs to be investigated in this article were synthesized by vapour-solid (VS) process. In principle, thermal evaporation technique is a simple process in which condensed or powder source material is vapourized at elevating temperature, then the resultant vapour phase is condensed under certain parameters mentioned previously (section 2.3) to form the desired product. The growth processes are carried out in a horizontal three zone tube furnace (SWGL1600X/MTI Corp.) as shown in schematic diagram of figure 1 , which is composed of a horizontal tube furnace with quartz tube $(3 \mathrm{~cm}$ diameter and $120 \mathrm{~cm}$ long), rotary pump system and digital mass flow metres control system, through which gases are supplied. The right-hand end of the quartz tube is connected to the rotary pump. Both ends are sealed with rubber O-rings (Viton) through stainless-steel screw connectors. The ultimate vacuum pressure for this configuration is $\sim 2 \times 10^{-3}$ Torr, measured by Edward vacuum gauge connected to a digital vacuum controller. The carrier gas is introduced from the left end of the quartz tube and is pumped out at the right end. The source material is a very fine pure Zn powder (Alfa Aesar Supplier), loaded on an alumina boat and positioned at the highest temperature region of the quartz tube. The pre-cleaned ITO-glass substrates were placed at a distance downstream for collecting growth products. This simple set-up can achieve high control of the final product.

\subsection{Characterization techniques}

The crystal structures of $\mathrm{ZnO}$ films were characterized by $\mathrm{X}$-ray diffractometer (Pan analytical Thin film/small-angle $\mathrm{X}$-ray diffraction $(\mathrm{SAXS}))$ with $\mathrm{CuK} \alpha(\lambda=0.1546 \mathrm{~nm})$ radiation. The surface morphologies of the $\mathrm{ZnO}$ films were observed by scanning electron microscope (SEM/JEOLJSM 5140) equipped with energy dispersive X-ray spectrometer (EDX). High-resolution transmission electron microscope, TEM JEOL-2000 EX, $200 \mathrm{kV}$, equipped with EDX was used to analyse the $\mathrm{ZnO}$ nanostructures.

\section{Results and discussion}

The main purpose of this investigation is to find the optimum CVD parameters to grow VA with long, small diameter and high-density ZnO NWs on ITO-coated glass. These parameters can simply be obtained by varying the flow rate of argon and oxygen gases, the position of the substrates and the growth time. The growth experiments were conducted at

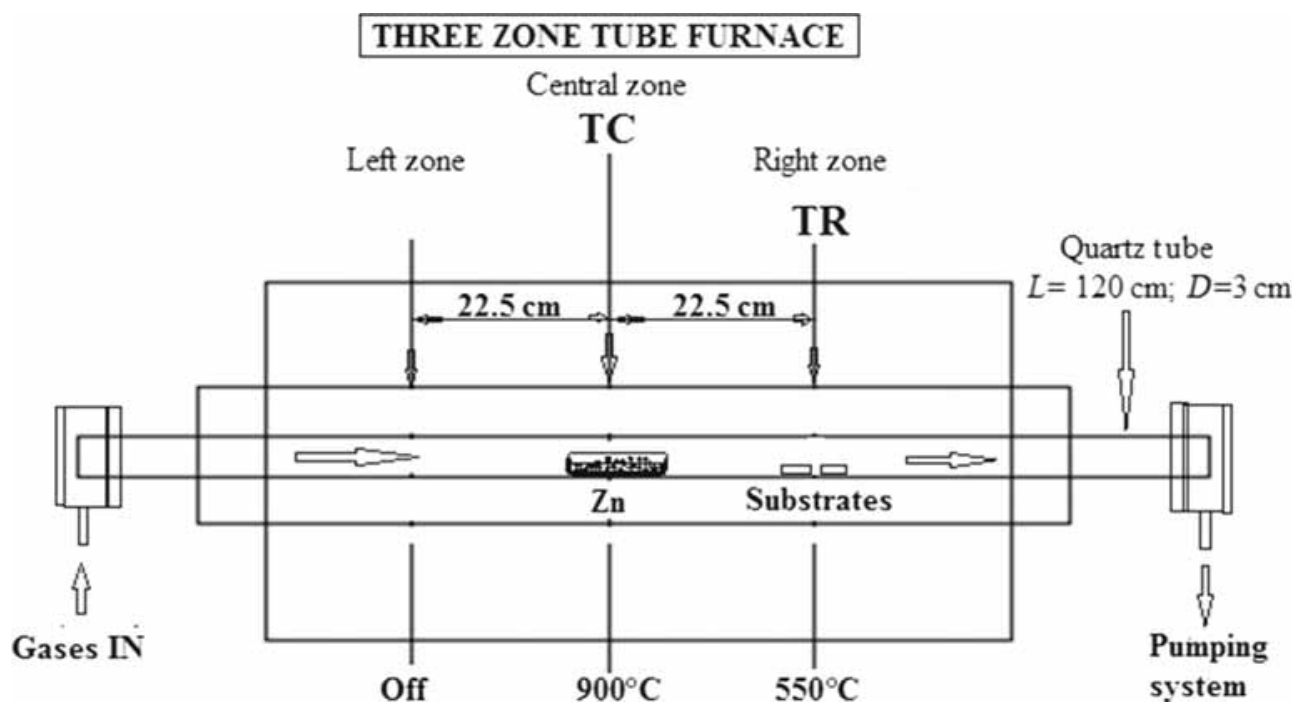

Figure 1. Schematic diagram of the experimental apparatus for growth of oxide nanostructures by the solid-vapour phase process. 
constant value of $\mathrm{ZnO}$ seed layer concentration. The central and right zone temperatures of the tube furnace were kept constants during the experiments. The growth of ZnO NWs as a function of argon and oxygen flow rates, substrate position, time and oxygen flow rate variations was investigated.

\subsection{Growth of $\mathrm{ZnO} \mathrm{NWs}$ as a function of $\mathrm{Ar}$ and $\mathrm{O}_{2}$ gases variation}

The first group of investigation was carried out to study the growth $\mathrm{ZnO} \mathrm{NWs}$ by varying the flow rates of $\mathrm{Ar}$ and $\mathrm{O}_{2}$ gases at fixed ratios of $\mathrm{Ar} / \mathrm{O}_{2}, 100 / 10,200 / 20$ and 300/30, under the following fixed conditions: weight of $\mathrm{Zn}$ powder is $2 \mathrm{~g}$, furnace temperature at the centre $\mathrm{TC}=900^{\circ} \mathrm{C}$ and at the right side $\mathrm{TR}=550^{\circ} \mathrm{C}$ (figure 1), reaction time $20 \mathrm{~min}$, and the final growth pressure of 100 Torr. Figures 2-4 show the SEM images of as-synthesized $\mathrm{ZnO}$ NWs under various flow rates of argon to oxygen gases. The SEM results show that long, VA and high-density $\mathrm{ZnO}$ NWs with different diameters have been synthesized. The average length of $\mathrm{ZnO} N W \mathrm{~s}$ was measured to be about $5 \mu \mathrm{m}$ at various flow rates of $\mathrm{Ar}$ and $\mathrm{O}_{2}(100 / 10,200 / 20$ and 300/30), while the average diameters of the wires decreased from 200 to $40 \mathrm{~nm}$ for S1 and from 120 to $25 \mathrm{~nm}$ for $\mathrm{S} 2$, respectively, as explained in table 1. Two conclusions have to be mentioned here, the first one is that the variation in gases flow rates have no effect on the length of the wire. The second one is related to decreasing of wire diameters, which is due to the temperature decreasing of samples position of S1 to S2. So, it could be ruled that sample position at lower temperature has smaller diameter

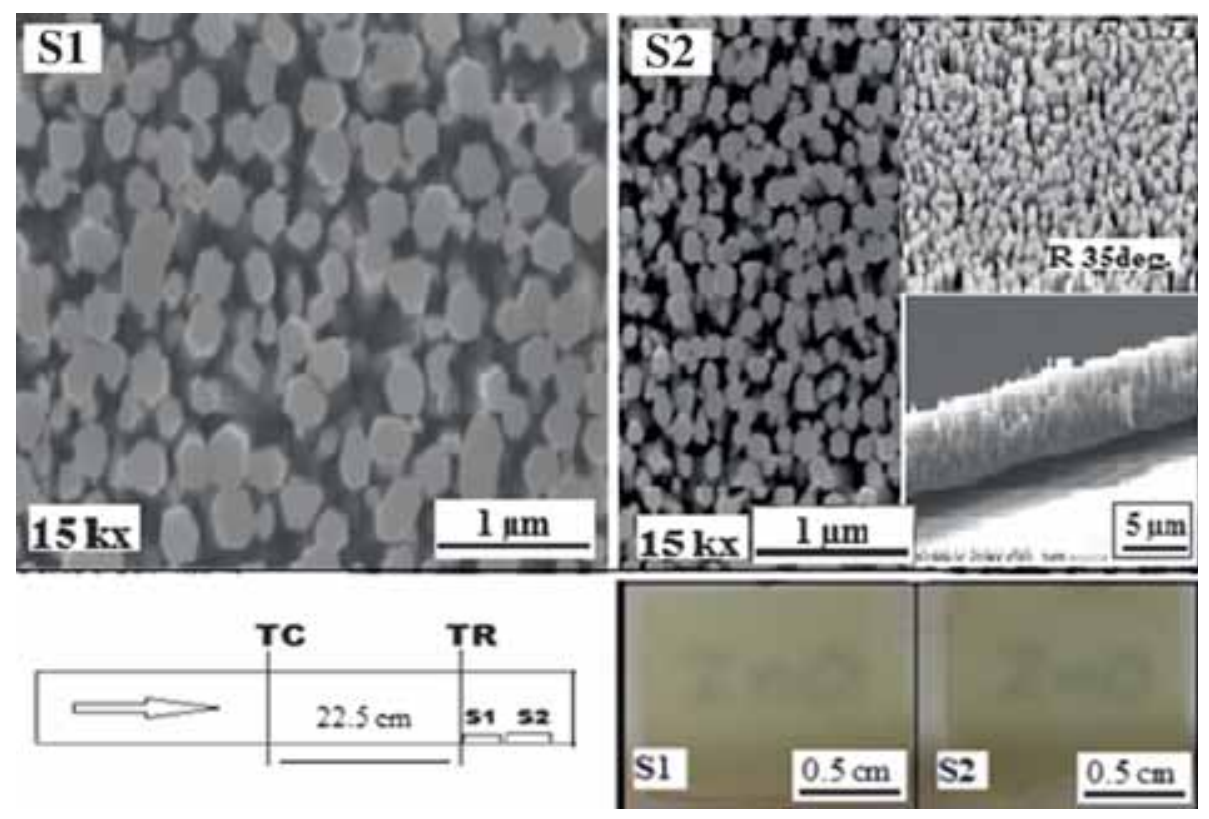

Figure 2. SEM images for ZnO NWs growth on ITO-glass at argon to oxygen $=100 / 10 \mathrm{sccm}$ for $20 \mathrm{~min}$ at $550^{\circ} \mathrm{C}$.
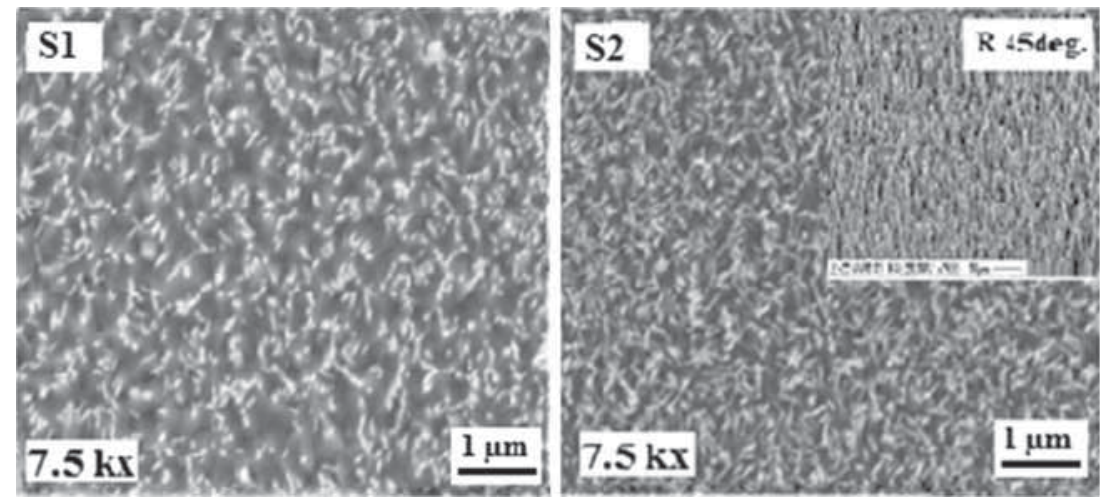

Figure 3. SEM images of ZnO NWs growth on ITO-glass at argon to oxygen flow rate $=200 / 20 \mathrm{sccm}$ for $20 \mathrm{~min}$ at $550^{\circ} \mathrm{C}$. 

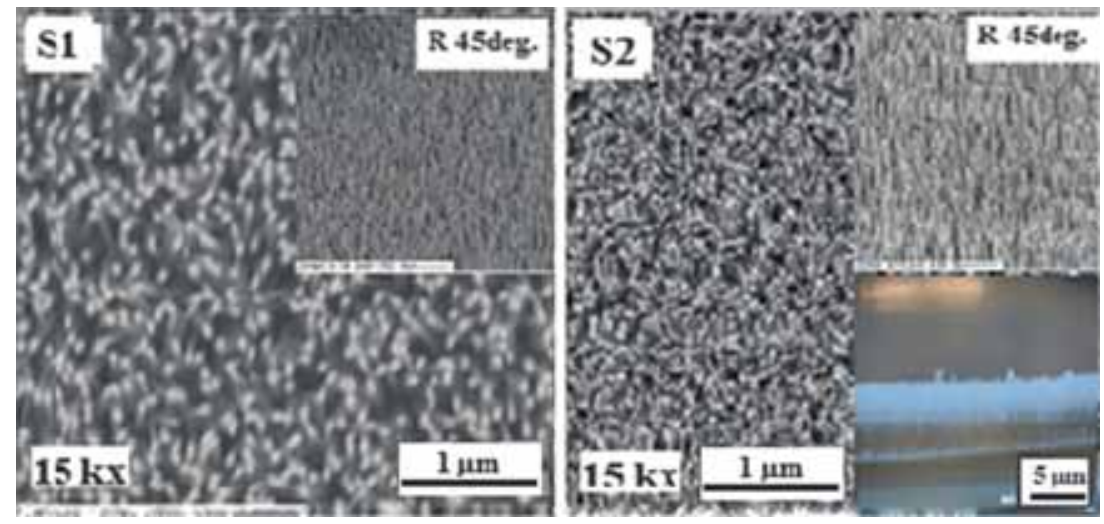

Figure 4. SEM images of ZnO NWs growth on ITO-glass at argon to oxygen flow rate $=300 / 30 \mathrm{sccm}$ for $20 \mathrm{~min}$ at $550^{\circ} \mathrm{C}$.

Table 1. Morphology measurements of $\mathrm{ZnO}$ NWs grown on ITO-glass substrate at various $\mathrm{Ar}$ and $\mathrm{O}_{2}$ flow rates.

\begin{tabular}{lcccccc}
\hline $\begin{array}{l}\text { Exptal. } \\
\text { code no. }\end{array}$ & Ar/O2 & $\begin{array}{c}\text { ZnO NWs } \\
\text { length }(\mu \mathrm{m})\end{array}$ & $\begin{array}{c}\text { Average } \\
\text { diameter of S1 (nm) }\end{array}$ & $\begin{array}{c}\text { Average } \\
\text { diameter of S2 (nm) }\end{array}$ & $\begin{array}{c}\text { Aspect } \\
\text { ratio L/D }\end{array}$ & SEM morphology \\
\hline CVD 24/Fig. 2 & $100 / 10$ & 5 & 200 & 120 & 25 & Wires with hexagonal C.S \\
CVD 26/Fig. 3 & $200 / 20$ & - & 80 & 40 & 25 & Wires with tipped ends \\
CVD 25/Fig. 4 & $300 / 30$ & 5 & 40 & 200 & Wires with circular C.S \\
\hline
\end{tabular}

(a)
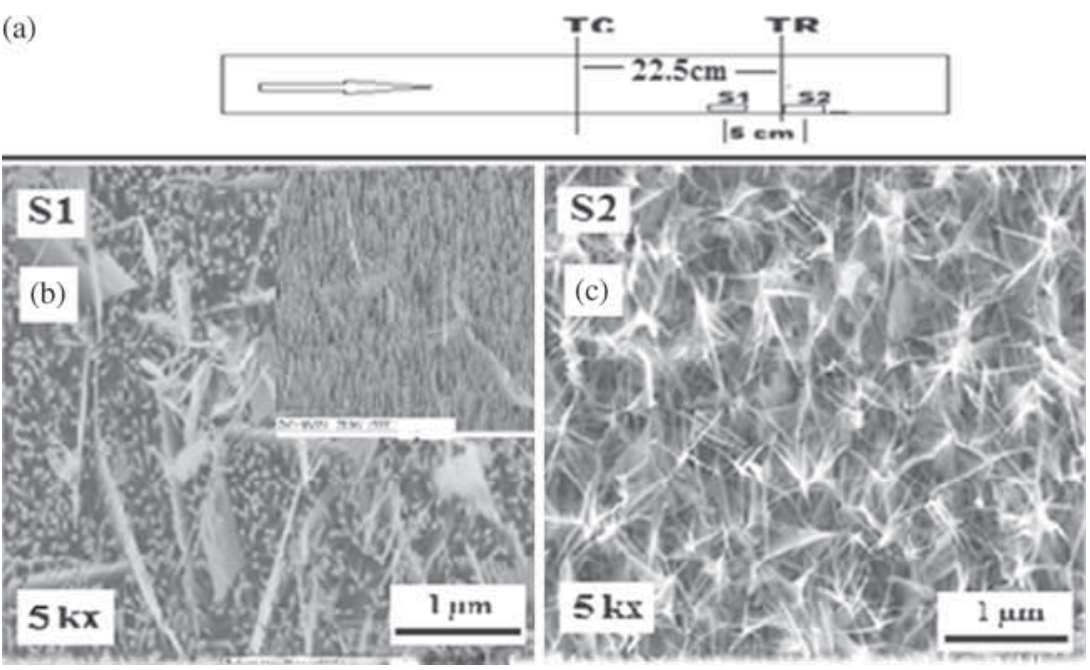

Figure 5. SEM images of ZnO NWs growth on ITO-glass; (a) sketch of substrate position, (b) S1: high density of VA ZnO NWs and comb-like nanostructures; and (c) S2: high density of ZnO NWs and fish bone-like nanostructures.

and vice versa. This could be due to the seed layer grain size variation as a function of temperature and large grains with high temperature and vice versa. The lengthy and VA NWs are shown in the insets of figures 2 and 4 . High aspect ratio $(L / D)$ can be obtained from 25 to 200. The NWs shown in figure 2 for $\mathrm{S} 1$ sample are all separated and have different diameters and the top $\mathrm{ZnO} \mathrm{NWs}$ are clearly flat with hexagonal shape. This confirms that nonanalytic growth with cleaned surface were synthesized. So, no metal catalyst was used to grow VA ZnO NW arrays. This suggested VS model to grow these NW arrays. Figure 2 shows an optical micrograph of typical $\mathrm{ZnO} \mathrm{NWs}$ grown on ITO-glass with semi-transparent and yellowish colour. Moreover, the major benefit of this investigation is to offer the possibility of 
growing $\mathrm{ZnO} \mathrm{NWs}$ at short growth time of $20 \mathrm{~min}$ and higher at the indicated parameters. Hence, increase in the growth time could be reflected on the length of the NWs.

\subsection{Growth as a function of substrate position variation}

The second group of investigation was carried out to study the substrate position influences on the morphology of $\mathrm{ZnO}$ nanostructures growth. The substrate positions can be regarded as temperature variation relative to the source materials position. So, higher temperature was obtained when the substrates were closer to the source material and vice versa. This could be mostly affected by the morphology of the nanostructures growth. In addition, the vertical growth mode is also investigated relative to the substrate position and their mechanism will be discussed later. Figure 5 shows SEM images for two samples (S1 and S2) corresponding to the positions of the samples explained in figure 5a. SEM images in figure $5 \mathrm{~b}$ demonstrates the growth of sample S1 positioned at a distance of $18 \mathrm{~cm}$ from TC, which shows a very small VA ZnO NWs as a first layer (VA ZnO NWs at the inset on top corner) and low-density comb-like nanostructure grown on the top of the NWs. Figure 5c also shows another $\mathrm{ZnO}$ fish-like bone nanostructure. This study proves that different substrate positions results in different morphologies

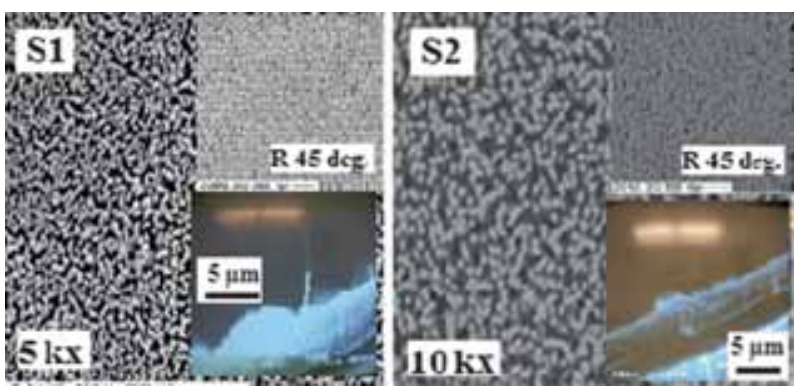

Figure 6. SEM images of $\mathrm{ZnO} N W$ s growth on ITO-glass/40 min $15 \mathrm{mM}, \mathrm{Zn}=3 \mathrm{~g}$ (insets represent images at $45^{\circ}$ and cross-sections). of $\mathrm{ZnO}$ nanostructures. The present result is different compared with the previous investigation explained in section 3.1 .

The main reason for these different morphologies is the saturation vapour pressures of $\mathrm{Zn}$. This is varied with respect to the substrate positions.

\subsection{Growth of ZnO NWs as a function of time variation}

The third group of investigation was carried out to study the time variation under constant $\mathrm{Ar}$ to $\mathrm{O}_{2}$ flow rates of 300 to $30 \mathrm{sccm}$, respectively. The growth of $\mathrm{ZnO} \mathrm{NWs}$ was conducted at central zone temperature of $900^{\circ} \mathrm{C}$ and right zone temperature of $550^{\circ} \mathrm{C}$ at reaction times of 20,40 and $60 \mathrm{~min}$, respectively. The substrate position was kept at $22.5 \mathrm{~cm}$ from the source material location (Zn powder at TC) as explained in figure 1. Figures 6 and 7 show the SEM images, which revealed the effect of growth time on the morphology of $\mathrm{ZnO}$ nanostructures. The dependence of NWs average length on the reaction time is shown in figure 8 . The length of NWs increased slightly when the growth time increased from 20 to $60 \mathrm{~min}$. The $\mathrm{ZnO}$ NWs synthesized at 20, 40 and $60 \mathrm{~min}$ have lengths of 5,5 and $7 \mu \mathrm{m}$, respectively (figure 8). Compared to those grown for a shorter time, the average diameter did not change significantly, indicating that the growth
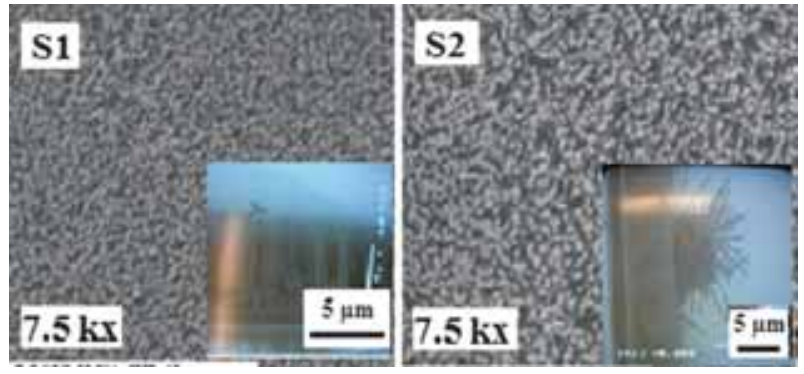

Figure 7. SEM images of $\mathrm{ZnO} \mathrm{NWs}$ growth on ITO-glass/ $60 \mathrm{~min} 15 \mathrm{mM}, \mathrm{Zn}=4 \mathrm{~g}$ (insets represent cross-sections).
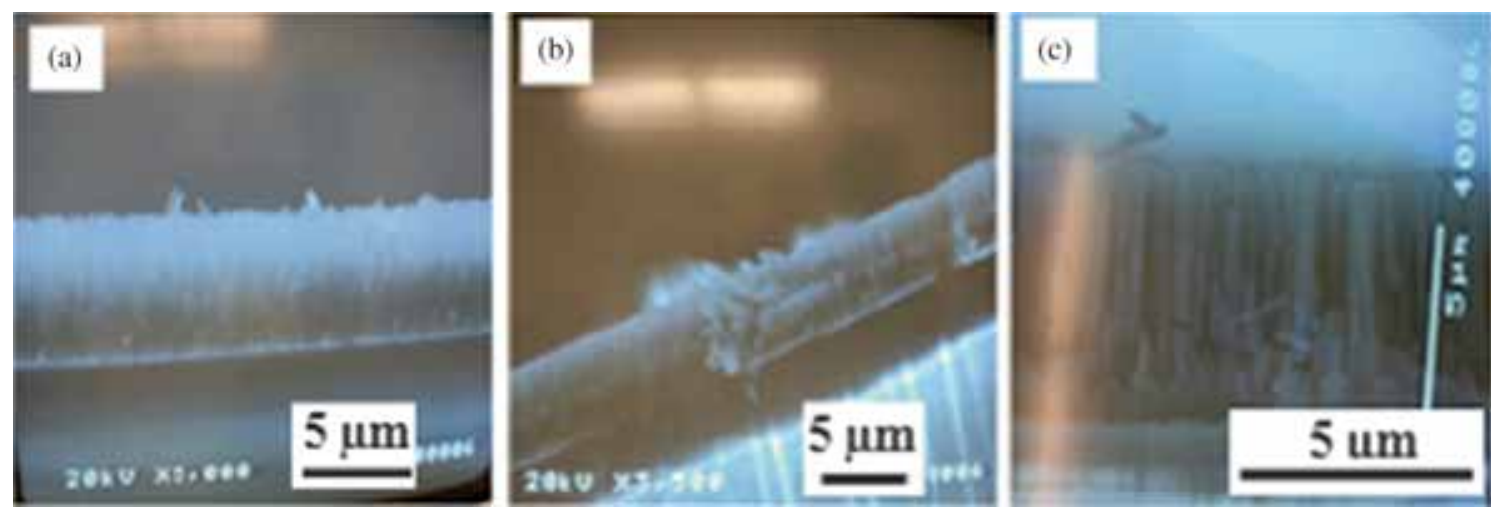

Figure 8. SEM cross-sectional images of ZnO NWs growth on ITO-glass with wire lengths of (a) 5, (b) 5, (c) $7 \mu \mathrm{m}$, at various growth times 20,40 and $60 \mathrm{~min}$, respectively. $\mathrm{Ar} / \mathrm{O}_{2}=300 / 30 \mathrm{sccm}$. 


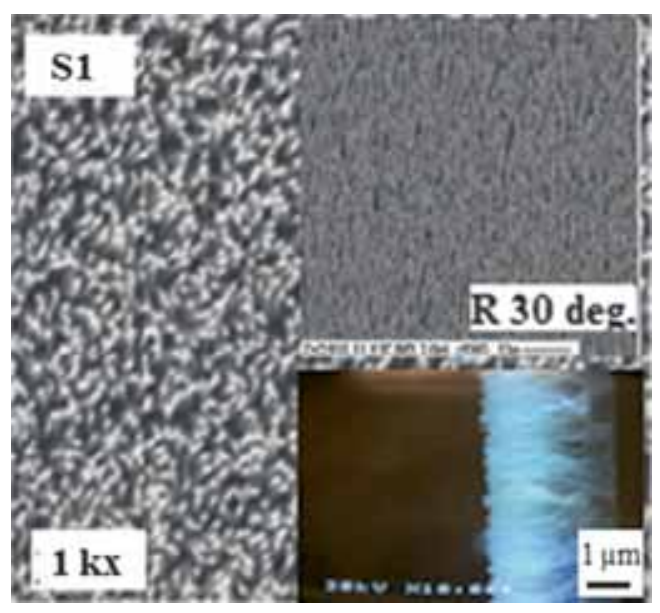

Figure 9. SEM images of $\mathrm{ZnO}$ NWs growth on ITO-glass/60 min, $\mathrm{Ar} / \mathrm{O}_{2}=300 / 40 \mathrm{sccm}$, at $550^{\circ} \mathrm{C}$ (inset shows film tilted at $30^{\circ}$ ).

time had a greater influence on the length of NW than the diameter.

\subsection{Growth of $\mathrm{ZnO} \mathrm{NWs}$ as a function of $\mathrm{O}_{2}$ rate flow variation}

The fourth group of investigation was to study the effect of $\mathrm{O}_{2}$ gas flow rates variation on the length and morphology of the synthesized $\mathrm{ZnO}$ NWs. These experiments were conducted by varying the $\mathrm{O}_{2}$ flow rate of 40,50 and $60 \mathrm{sccm}$ under the following fixed conditions: argon gas flow rate of $300 \mathrm{sccm}$, furnace temperatures of $\mathrm{TC}=900^{\circ} \mathrm{C}$ and $\mathrm{TR}=$ $550^{\circ} \mathrm{C}$ for $60 \mathrm{~min}$ reaction time, and final growth pressure of 100 Torr. Figures 9, 10, and 11 show fine NWs synthesized under gas flow rates ratio of 300/40,300/50 and 300/60, respectively. It can be seen that high-density NWs have been produced. The typical NWs appear to grow straight and VA on the ITO-glass substrate coated with $\mathrm{ZnO}$ seed layer, as demonstrated in figure 10 .

Figure 12 shows collection data for comparison of SEM cross-sections of as-synthesized $\mathrm{ZnO} \mathrm{NWs}$ on ITO-glass under constant argon gas flow rate of $(300 \mathrm{sccm})$, with various oxygen gas flow rates of 40, 50 and $60 \mathrm{sccm}$. Global data for average length of $\mathrm{ZnO}$ NWs grown on ITO-glass via CVD technique at a certain growth parameter were drawn as a histogram shown in figure 13. Typical wires length around $10 \mu \mathrm{m}$ at $50 \mathrm{sccm}$ rate flow of oxygen gas and constant argon rate flow of $300 \mathrm{sccm}$ can be observed. This is considered as optimum values achieved in the present investigations. It was found that the wire length is very sensitive to the flow rate of oxygen in the growth system.

\subsection{Typical structure and morphology analysis of $\mathrm{ZnO} \mathrm{NWs}$}

X-ray diffraction (XRD) was employed to investigate the crystal structure of the $\mathrm{ZnO}$ NWs. Figure 14 shows
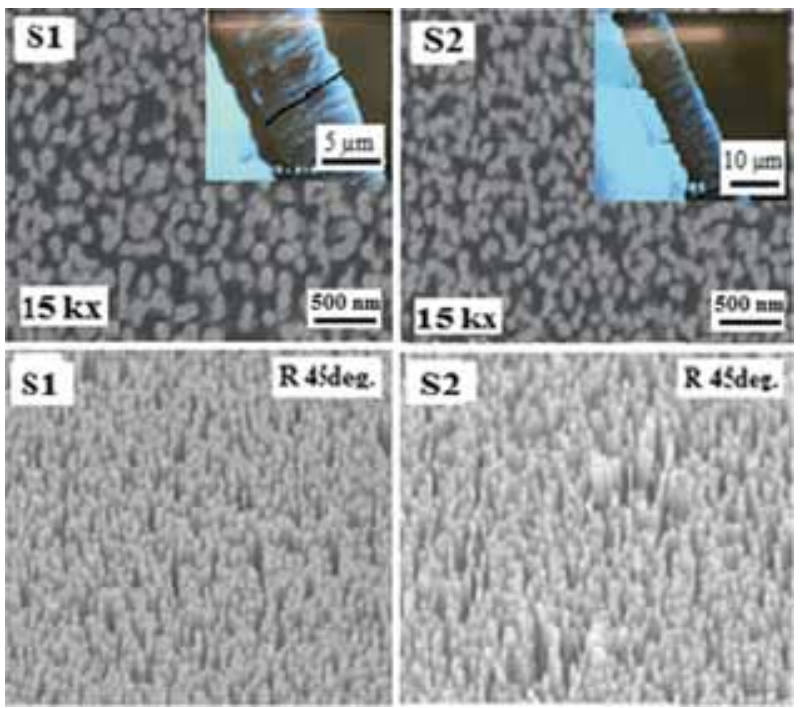

Figure 10. Typical SEM images of $\mathrm{ZnO}$ NWs on ITO-glass grown at $60 \mathrm{~min}$. $\mathrm{Ar} / \mathrm{O}_{2}=300 / 50 \mathrm{sccm}$, average diameters: $\mathrm{S} 1=$ $95, \mathrm{~S} 2=70 \mathrm{~nm}$.

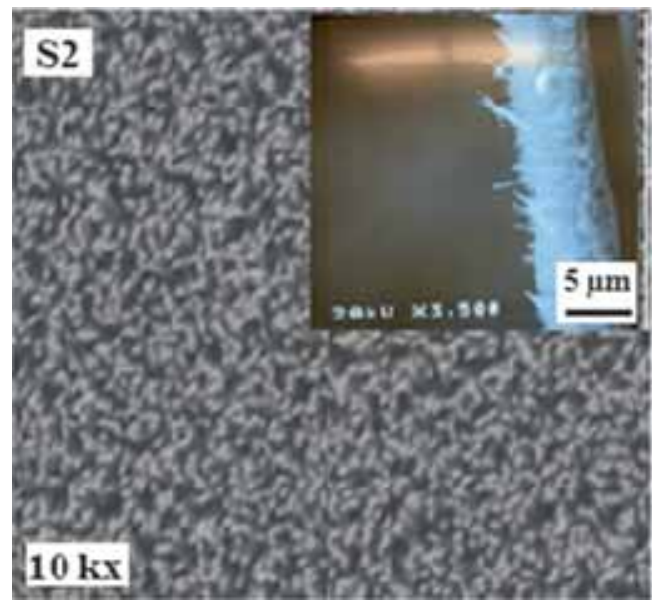

Figure 11. SEM image of $\mathrm{ZnO}$ NWs grown on ITO-glass/60 min, $15 \mathrm{mM}, \mathrm{Zn}=4 \mathrm{~g}$ (inset shows cross-section $=7 \mu \mathrm{m}$ ).

typical XRD patterns of ZnO NWs on ITO-glass as synthesized via CVD method. It was found that only one strong $\mathrm{ZnO}\left(\begin{array}{lll}0 & 0 & 2\end{array}\right)$ diffraction peak with small line width was observed in the spectrum. This diffraction peak at $2 \theta=$ $34.93^{\circ}$ can be easily assigned to a $\mathrm{ZnO}$ hexagonal wurtzite structure. The XRD peak is slightly shifted to higher angle for $\mathrm{ZnO}$ (002). This shift could be due to small strain generation in the materials structure during synthesis. There is no peak from other impurities, such as Zn metal that are detected in the patterns, indicating that the product is formed with high purity.

Transmission electron microscopy (TEM) was employed to characterize the as-synthesized $\mathrm{ZnO}$ NWs. Very small amount of this product was scraped from the ITO top surface. These $\mathrm{ZnO}$ NWs were prepared on $3.05 \mathrm{~mm}$ formvar-coated copper grid. The TEM image in figure $15 \mathrm{a}$ and $\mathrm{b}$ shows the 

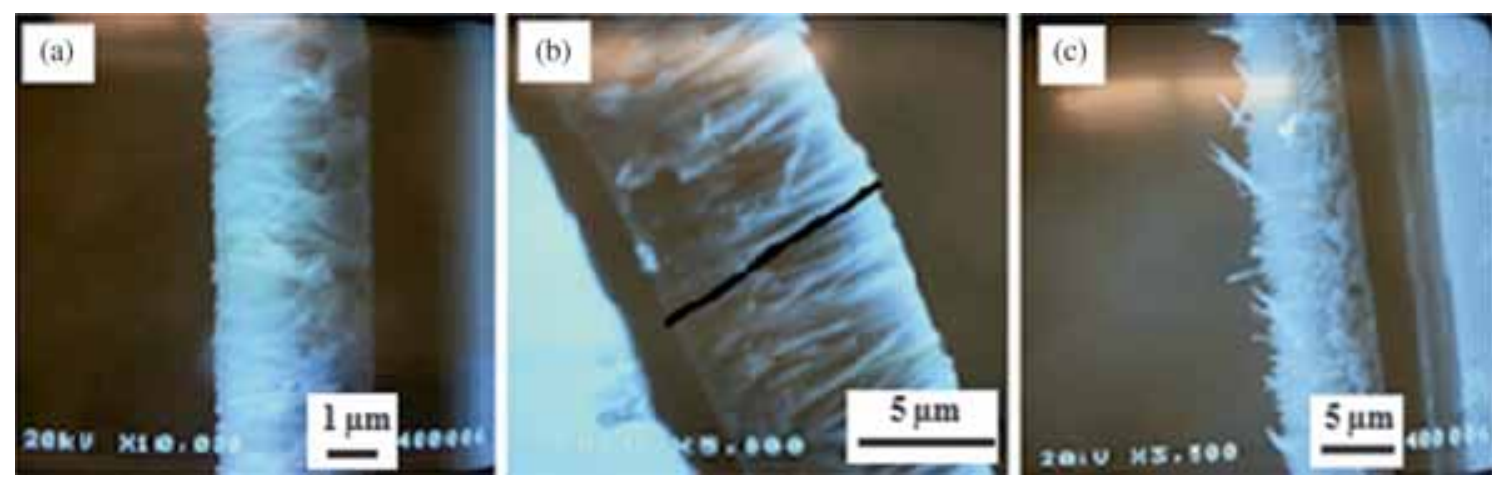

Figure 12. Summarized cross-sections of ZnO NWs grown on ITO with wire lengths of (a) 3, (b) 10 and (c) $7 \mu \mathrm{m}$ at constant argon flow rates of $300 \mathrm{sccm}$ and various $\mathrm{O}_{2}$ flow rates of 40, 50 and $60 \mathrm{sccm}$, respectively.

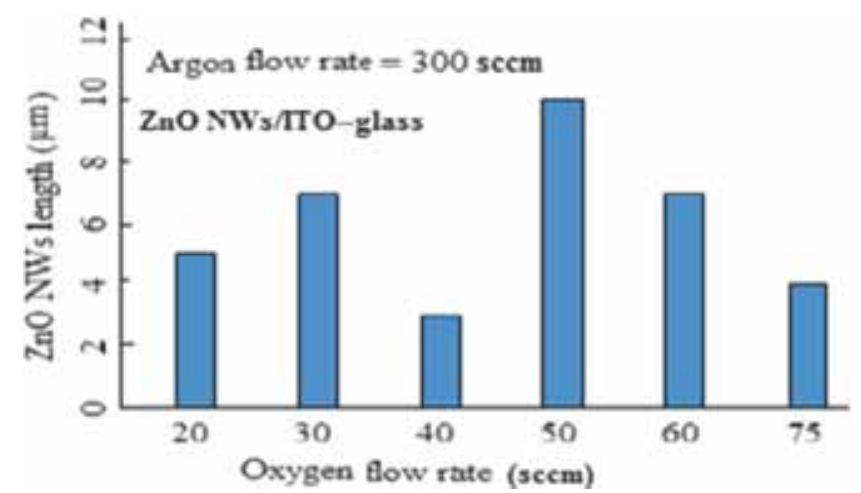

Figure 13. Histogram of average length of $\mathrm{ZnO}$ NWs $v s$. oxygen gas flow rate. At fixed argon flow rate of $300 \mathrm{sccm}$ and $60 \mathrm{~min}$ growth time.

clusters and individual $\mathrm{ZnO}$ NWs, respectively. TEM images also show that the diameter size is varied significantly along the wire length. The measured diameters of $\mathrm{ZnO} \mathrm{NWs}$ are 100 and $150 \mathrm{~nm}$ for top and bottom, respectively. Figure $15 \mathrm{c}$ shows an EDX spectrum of the ZnO NWs. Features of Zn and $\mathrm{O}$ atoms can be observed in this spectrum. The appearance of $\mathrm{Cu}$ peak in the spectrum is due to the TEM copper grid. The EDX detection of just $\mathrm{Zn}$ and $\mathrm{O}$ atoms confirms the high purity of the prepared $\mathrm{ZnO}$.

Figure 16 demonstrates the high quality of the assynthesized $\mathrm{ZnO} \mathrm{NW}$ s arrays grow with a $c$-axis orientation perpendicular to the substrate. Typical SEM image of $\mathrm{ZnO}$ NWs is shown in figure 16a. The single ZnO NWs and its related selected area electron diffraction pattern is shown in figure 16b. It is suggested that the $\mathrm{ZnO}$ NWs shows the excellent preferred (002) reflection. This is previously confirmed by XRD analysis, as shown in figure 14 .

$\mathrm{ZnO}$ NWs can be synthesized with a growth time from 20 to $60 \mathrm{~min}$, and the length of NWs is mainly determined by the growth time. The longest NWs have average length of around $10 \mu \mathrm{m}$ and average diameter of $100 \mathrm{~nm}$. ZnO NWs cannot be formed unless the growth temperature at the precursor is $900^{\circ} \mathrm{C}$. The $\mathrm{ZnO} \mathrm{NWs} \mathrm{made} \mathrm{in} \mathrm{this} \mathrm{method} \mathrm{are} \mathrm{VA,}$ and have small wire diameter, long length and high density,

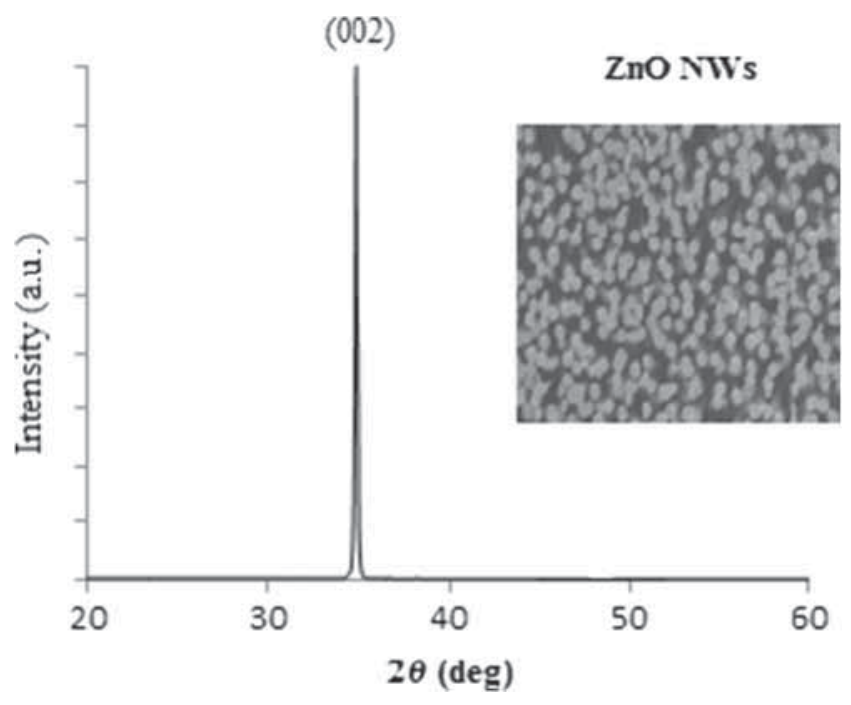

Figure 14. XRD of typical $\mathrm{ZnO}$ NWs on ITO-glass as synthesized via CVD method.

which are suitable for building hybrid metal oxide/organic solar cells on ITO- and FTO-coated glass substrates as the substrate temperatures are equal to $550^{\circ} \mathrm{C}$.

\subsection{Growth model and mechanism of VA ZnO NWs/NRs}

$\mathrm{ZnO}$ has the wurtzite structure, as shown in figure $17 \mathrm{a}$, which has a hexagonal unit cell with space group C6mc and lattice parameters $=0.396$ and $c=0.52065 \mathrm{~nm}$. The oxygen anions and $\mathrm{Zn}$ cations form a tetrahedral unit. The entire structure lacks central symmetry. Figure 17 a shows the $\mathrm{ZnO}$ crystal, which consists of an alternating sequence of hexagonally closed-packed layers of $\mathrm{Zn}^{2+}$ and $\mathrm{O}^{2-}$ ions along the c-direction. The $\mathrm{ZnO}\{0001\}$ faces have the highest energy and low index planes. The growth model of VA $\mathrm{ZnO}$ NWs on ITO-glass substrate depends on the texture of $\mathrm{ZnO}$ seed layer, zero lattice mismatch between $\mathrm{ZnO}$ nanoparticles as a seed layer and the ZnONWs grown. VA ZnO NWs or NRs can be synthesized by heteroepitaxy or homoepitaxy growth. 

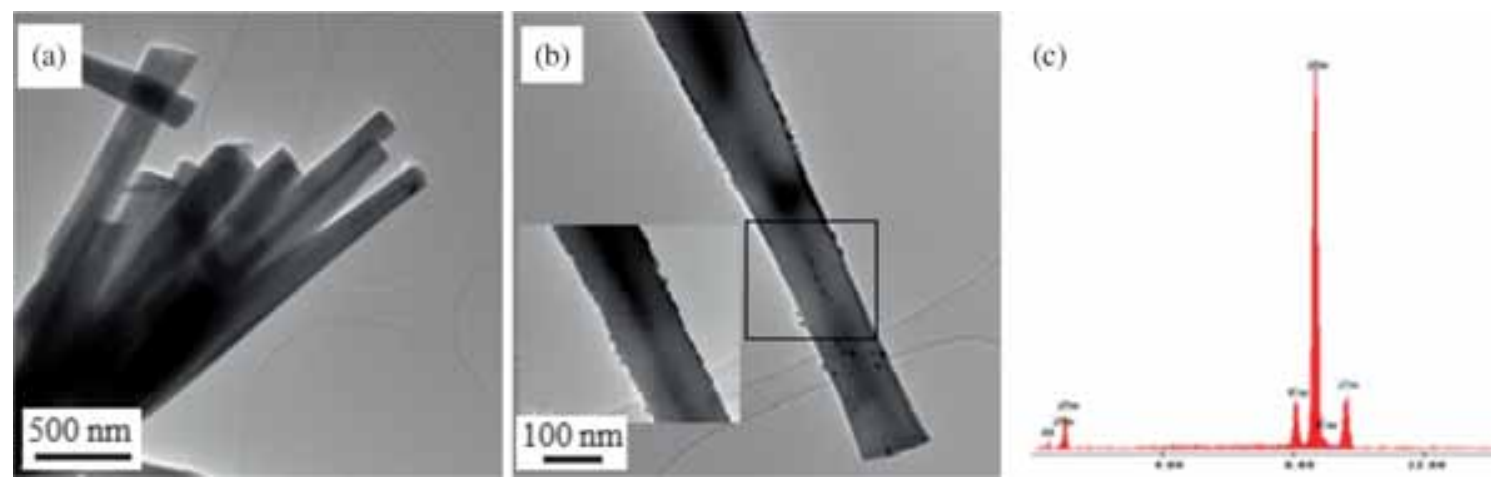

Figure 15. TEM images of (a) clusters of ZnO NWs, (b) single $\mathrm{ZnO}$ NWs, and the inset shows magnified image. (c) EDX spectrum measured for $\mathrm{ZnO}$ nanowires.
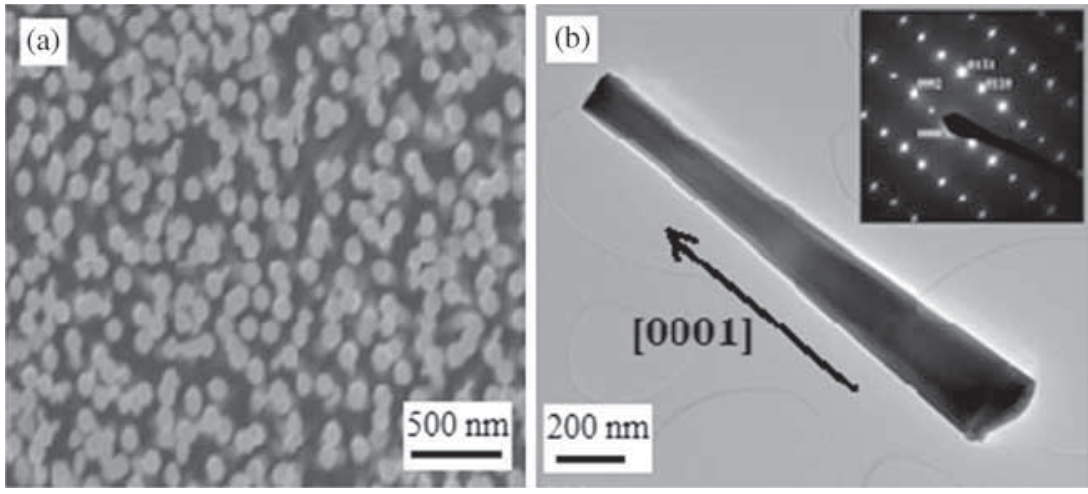

Figure 16. (a) SEM-top view image of typical $\mathrm{ZnO} \mathrm{NWs}$ and (b) TEM images of single-crystalline $\mathrm{ZnO} \mathrm{NWs}$ (inset is the corresponding SAED pattern of the $\mathrm{ZnO}$ NWs).

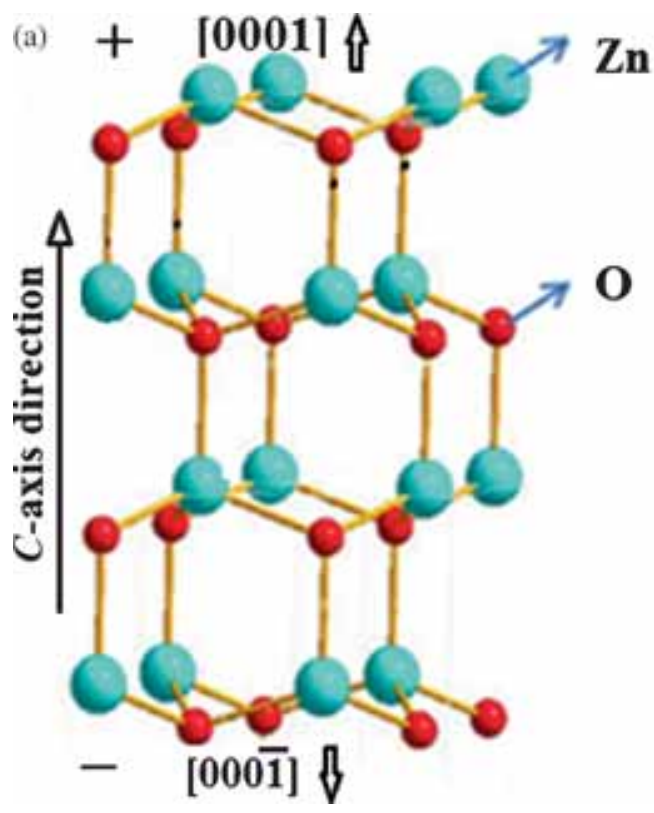

(b)

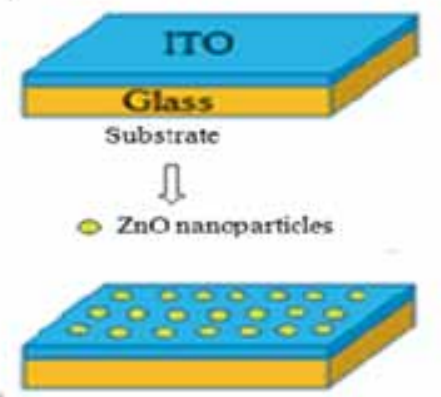

Highly oriented ZnO seed layer on substrate along, the c-axis \3

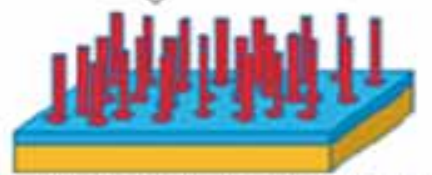

VAZnO NWs/NRs along [0001]

Figure 17. (a) Wurtzite crystal structure model of $\mathrm{ZnO}$ and (b) $\mathrm{ZnO}$ NWs growth mechanism process. 
In heteroepitaxy growth, substrates with a small lattice mismatch between $\mathrm{ZnO}$ NWs are needed to provide a good template for VA ZnO NWs. In the present work, homoepitaxy growth with highly (0002) oriented $\mathrm{ZnO}$ seeds layer facilitate the aligned growth of $\mathrm{ZnO} \mathrm{NWs}$. It is well known that $\mathrm{ZnO}$ wetting layer formed prior to NWs/NRs growth has been reported by many authors $[33,34]$. Figure $17 \mathrm{~b}$ demonstrates the growth process of $\mathrm{ZnO} \mathrm{NWs}$ on $\mathrm{ZnO}$ seed layer.

\section{Conclusions}

In this study, ZnO NWs were synthesized on ITO-coated glass substrate by a CVD technique. The formation of the VA $\mathrm{ZnO} \mathrm{NWs}$ was supported by $\mathrm{ZnO}$ seeding layer on the ITO substrate at growth temperature of $550^{\circ} \mathrm{C}$ under argon and oxygen gases flows. The CVD parameters variation results in a typical and optimized parameters of $\mathrm{ZnO} \mathrm{NWs}$ growth of VA, long, high density and small diameters. These were mainly analysed with SEM and XRD for the synthesized ZnO NWs by CVD method. The XRD and energy-dispersive $\mathrm{X}$-ray spectroscopy analyses for typical sample clearly indicates that well-ordered single crystal along the $c$-axis with highly pure $\mathrm{ZnO}$ NWs are formed. The TEM analysis confirmed the XRD results. It was found that in typical conditions the measured length of these NWs was around $10 \mu \mathrm{m}$, while the diameters were in between 50 and $100 \mathrm{~nm}$. The growth model confirmed the epitaxial growth of VS mechanism. The benefit of this technique is to produce highquality, long and VA ZnO NWs, which can be applied on the electrode of dye-synthesized solar cell application.

\section{Acknowledgements}

We would like to acknowledge the financial support via the Department of State/USA/CRDF/ISFP and the opportunity afforded by the University of Technology, Baghdad, Iraq. We also thank Dr W Zhou and his group at AMIRI/University of New Orleans/Louisiana and for the benefit of using their materials and equipment, and for giving us the useful suggestions for research.

\section{References}

[1] Liu B and Zeng H C 2003 J. Am. Chem. Soc. 1254430

[2] Ibupoto Z H, Khun K, Eriksson M, AlSalhi M, Atif M, Ansari A and Willander M 2013 Materials 63584

[3] Foo K L, Hashim U, Muhammad K and Voon C H 2014 Nanoscale Res. Lett. 9429

[4] Lu L, Chen J, Li L and Wang W 2012 Nanoscale Res. Lett. 7293

[5] Hsiao C-C and Luo L-S 2014 Sensors 1412219

[6] Zhang Q, Dandeneau S C, Zhou X and Cao G 2009 Adv. Mater. 214087
[7] Yang W, Wan F, Chen S and Jiang C 2009 Nanoscale Res. Lett. 41486

[8] Ramachandran K, Kumar G G, Kim A R and Yoo D J 2014 Bull. Korean Chem. Soc. 351091

[9] Elamin N and Elsanousi A 2013 J. Appl. Ind. Sci. 132

[10] Rashidi H, Ahmadpour A, Bamoharram F F, Zebarjad S M, Heravi M M and Tayari F 2014 Chemical Papers 68516

[11] Zak A B, Majid W H A, Wang H Z, Yousefi R, Golsheikh A M and Ren Z F 2013 Ultrason. Sonochem. 20395

[12] Nayak A P, Katzenmeyer A and Gosho Y 2010 Proceedings of the national conference on undergraduate research (NCUR), University of Montana, Missoula, April 15-17

[13] Sornalatha D J and Murugakoothan P 2013 J. Emerg. Technol. Adv. Eng. 3414

[14] Khan Z R, Khan M S, Zulfequar M and Khan M S 2011 Mater. Sci. Appl. 2340

[15] Foo K L, Uda Hashim, Kashif Muhammad and Chun Hong Voon 2014 Nanoscale Res. Lett. 9429

[16] Prakashi T, Jayaprakash R, Neri G and Kumar S 2013 J. Nanomater. 20138

[17] Lu L, Chen J, Li L and Wang W 2012 Nanoscale Res. Lett. 7293

[18] Rodwihok C, Gardchareon A, Phadungdhitidhada S, Wongratanaphisan D and Choopun S 2014 Thai J. Phys. Series 1025001

[19] Hassan N K, Hashim M R, Mahdi M A and Allam N K 2012 ECS J. Solid State Sci. Technol. 186

[20] Ma T, Wang Y, Tang R, Yu H and Jiang H 2013 J. Appl. Phys. 113204503

[21] Dongshan Y, Tarek T, James T M J, Valentin C and Curtis R T 2010 Nanoscale Res. Lett. 51333

[22] Giri P K, Patel P K, Panchal C J et al 2007 Synth. React. Inorg. Metal-Org. Nano-Metal. Chem. 37437

[23] Khanlary M R, Vahedi V and Reyhani A 2012 Molecules 175021

[24] Greene L E, Yuhas B D, Law M, Zitoun D and Yang P 2014 Inorg. Chem. 457535

[25] Kim K H, Utashiro K, Abe Y and Kawamura M 2014 Int. J. Electrochem. Sci. 92080

[26] Kumar P S, Yogeshwari M, Raj A D, Mangalaraj D, Nataraj D and Pal U 2009 J. Nano Res. 5223

[27] Lucas M, Wang Z L and Riedo E 2010 Phys. Rev. B 81 045415

[28] Zhang N, Yi R, Shi R, Gao G, Chen G and Liu X 2009 Mater. Lett. 63496

[29] Yong-Zhe Z, Li-Hui W, Yan-Ping L, Er-Qing X, De Y and Jiang-Tao C 2009 Chin. Phys. Lett. 26038201

[30] Hughes W L and Wanga Z L 2005 Appl. Phys. Lett. 86043106

[31] Gui Z, Liu J, Wang Z, Song L, Hu Y, Fan W and Chen D 2005 J. Phys. Chem. B 1091113

[32] Wua C-Y, Hsua H-C, Chenga H-M, Yanga S and Hsieha W-F 2006 J. Cryst. Growth 287189

[33] Tasker P W 1979 J. Phys. C: Solid State Phys. 124977

[34] Greene L E, Law M, Tan D H, Montano Ma, Goldberge J, Gomorja G and Yang P 2005 Nano Lett. 51231 